УДК 338.012

DOI 10.18413/2687-0932-2020-47-3-512-521

\title{
Динамика развития авиаотрасли: тренды и пандемийные вызовы
}

\author{
Т.Б. Климова \\ Белгородский государственный национальный исследовательский университет, \\ Россия, 308015, г. Белгород, ул. Победы, 85 \\ E-mail: Tklimova@bsu.edu.ru
}

\begin{abstract}
Аннотация
В статье рассмотрена динамика развития авиаотрасли в «допандемийную эпоху» и сложившаяся ситуация в отрасли, связанная с распространением COVID-19 и его последствиями. Международная ассоциация воздушного транспорта (IATA) отметила, что никогда в истории авиационная отрасль не сталкивалась с подобной ситуацией. Для решения таких срочных проблем во всем мире принимаются скоординированные меры авиационных властей и бизнеса. В статье автор концентрирует внимание на том, что сгладить последствия нынешней экономической нестабильности без эффективной государственной поддержки не удастся. Менеджменту авиакомпаний, со своей стороны, также необходимо разрабатывать новые стратегии, научиться использовать новые инструменты и стандарты, перспективные технологии, мобилизовать все возможности для дальнейшего развития, которые непременно откроются, так как последствия кризиса приводят к необходимым для дальнейшего роста позитивным изменениям. Отмечено, что для достижения сбалансированного и эффективного перезапуска отрасли необходим глобальный подход, основанный на оценке мер по снижению рисков восстановления отрасли с необходимостью разблокировать экономику и обеспечить возможности пассажирских авиаперелетов.
\end{abstract}

Ключевые слова: авиакомпании, авиаперевозки, пассажиропоток, Международная ассоциация воздушного транспорта, пандемия.

Для цитирования: Климова Т.Б. 2020. Динамика развития авиаотрасли: тренды и пандемийные вызовы. Экономика. Информатика. 47 (3): 512-521. DOI 10.18413/2687-0932-2020-47-3-512-521.

\section{Dynamics of the aviation industry: trends and pandemic challenges}

\author{
T.B. Klimova \\ Belgorod State University, 85 Pobeda St, Belgorod, 308015, Russia \\ E-mail: Tklimova@bsu.edu.ru
}

\begin{abstract}
The article considers the dynamics of the aviation industry development in the "pre-pandemic era" and the current situation in the industry related to the spread of COVID-19 and its consequences. The International Air Transport Association (IATA) noted that the aviation industry has never faced such a situation in its history. To solve such urgent problems, coordinated measures are being taken by aviation authorities and businesses around the world. In the article, the author focuses on the fact that it will not be possible to smooth the consequences of the current economic instability without effective state support. Airline management, for its part, also needs to develop new strategies, learn to use new tools and standards, promising technologies, and mobilize all the opportunities for further development, which will certainly open up, as the consequences of the crisis lead to the positive changes necessary for further growth. It is noted that in order to achieve a balanced and effective restart of the industry, a global approach is needed, based on the assessment of measures to reduce the risks of restoring the industry with the need to unblock the economy and provide opportunities for passenger air travel.
\end{abstract}

Keywords: airlines, air transportation, passenger traffic, International Air Transport Association, pandemic.

For citation: Klimova T.B. 2020. Dynamics of the aviation industry: trends and pandemic challenges. Economics. Information technologies. 47 (3): 512-521. (in Russian). DOI 10.18413/2687-0932-2020-47-3-512-521. 


\section{Введение}

Глобализация способствовала развитию гражданской авиации, и последние десятилетия характеризовались достаточно быстрыми темпами еe роста. Открытие воздушного пространства и международного сообщения, введение безвизового режима и отмена пограничного контроля между многими странами, а также научно-технический прогресс положительно сказывались на всей авиационной отрасли, превратив ее в доступный и наиболее комфортабельный вид транспорта.

На конец 2018 года мировой пассажиропоток гражданской авиации увеличился с 1,4 млрд пассажиров в 1970 г. до 4,3 млрд пассажиров [Мальцев А.А., Матвеева А.В., 2018, Годовые доклады..., 2018, Статистические данные..., 2018].

Среди ярких событий этого периода в отрасли можно выделить [История развития..., Деловой авиационный портал, 2002]:

- ввод первого в мире дальнемагистрального широкофюзеляжного пассажирского самолета Boeing - 747 (в последующем были введены и другие модели Boeing и Airbus), позволившего в следующие годы увеличить максимальную дальность полета до 12400 км. (1970 г.);

- ввод первого беспосадочного рейса авиакомпании Cathay Pacific по маршруту Гонконг - Ванкувер, соединившего азиатский регион к западу от Японии с Северной Америкой (1980 г.);

- ввод первой программы лояльности для часто летающих пассажиров авиакомпании American Airlines (1981 г.);

- массовое появление бюджетных авиакомпаний - «лоукостеров» (1998 г);

- ввод самого длинного беспосадочного рейса из Гонконга в Лондон, протяжённость трассы - 21602 км., время в пути - 22 ч. 40 мин. (2005 г.);

- выпуск самолета Boeing 787, что в дальнейшем определило конкурентные позиции американской авиационной промышленности, которая с 2015 г. станет лидером по производству широкофюзеляжных пассажирских самолетов, выпуская примерно в два раза больше самолетов, чем европейский Airbus.

В настоящее время авиационный транспорт является важным инструментом развития мировой экономики.

\section{Объекты и методы исследования}

Объектом исследования в данной статье являются авиационная отрасль и авиакомпании, которые в настоящее время оказались в масштабной кризисной ситуации, вызванной пандемией COVID-19. Основными источниками для написания данной статьи послужили статистические данные и итоги исследований Всемирной туристской организации (UNWTO), данные исследований Международной организации гражданской авиации (ICAO), Международной ассоциации воздушного транспорта (IATA), рейтинги Британской консалтинговой компании SKYTRAX. Для всестороннего изучения объекта исследования использованы источники научных и периодических изданий по проблемам развития мирового рынка гражданской авиации и пассажирских авиационных перевозок, аналитические отраслевые обзоры, включая обзоры рынка авиаперевозок, подготовленные Объединенной авиастроительной корпорацией и представленные в открытых источниках. В статье использовались методологические подходы, в том числе концептуальные положения системного подхода, методы логического анализа и синтеза, а также методы дедукции, сравнительного анализа, анализа микроэкономической динамики, графической интерпретации данных.

\section{Результаты и их обсуждение}

Согласно данным ЮНВТО более 50 \% путешествий по всему миру приходится на долю авиатранспорта (800 млн туристов). Структура общемировых транспортных пассажирских перевозок туристов представлена на рис. 1 [International Tourism Highlights, 2019]. 


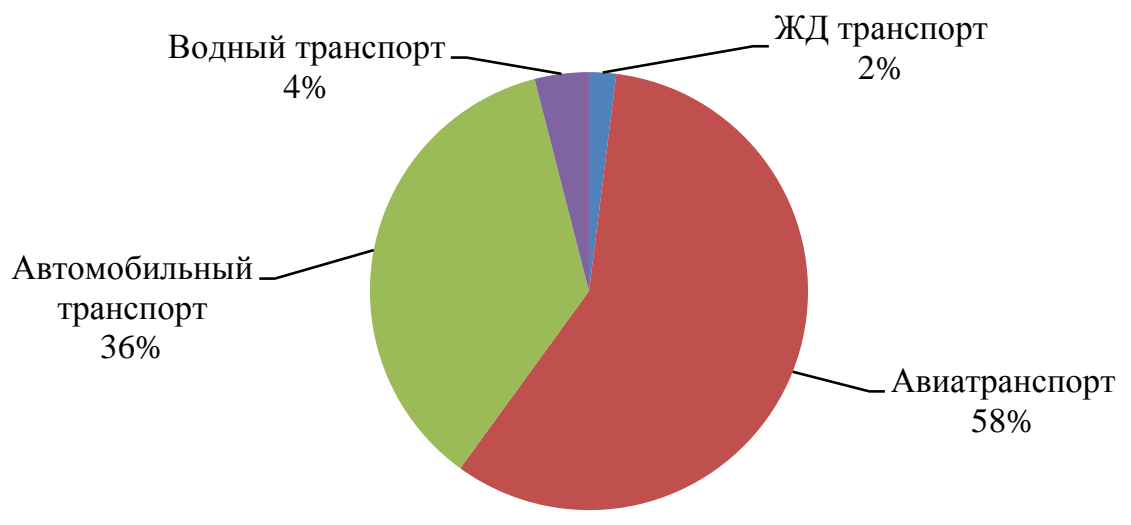

Рис. 1. Структура общемировых транспортных пассажирских перевозок туристов на 2018 г.

Fig. 1. Structure of global transport passenger transportation of tourists for 2018

В 2018 году благодаря устойчивому росту пассажирских перевозок было перевезено 4,3 млрд пассажиров регулярными авиарейсами, из которых 1,8 млрд (41\%) пассажиров пришлись на международные авиаперевозки и, соответственно, $59 \%$ составили внутрирегиональные перевозки [Статистические данные..., 2018].

Рост общемирового пассажиропотока в 2018 году по сравнению с предыдущим годом составил $6,4 \%$. (рис. 2).

пасс. млн. $\quad$ рост $\square$ занятость кресел

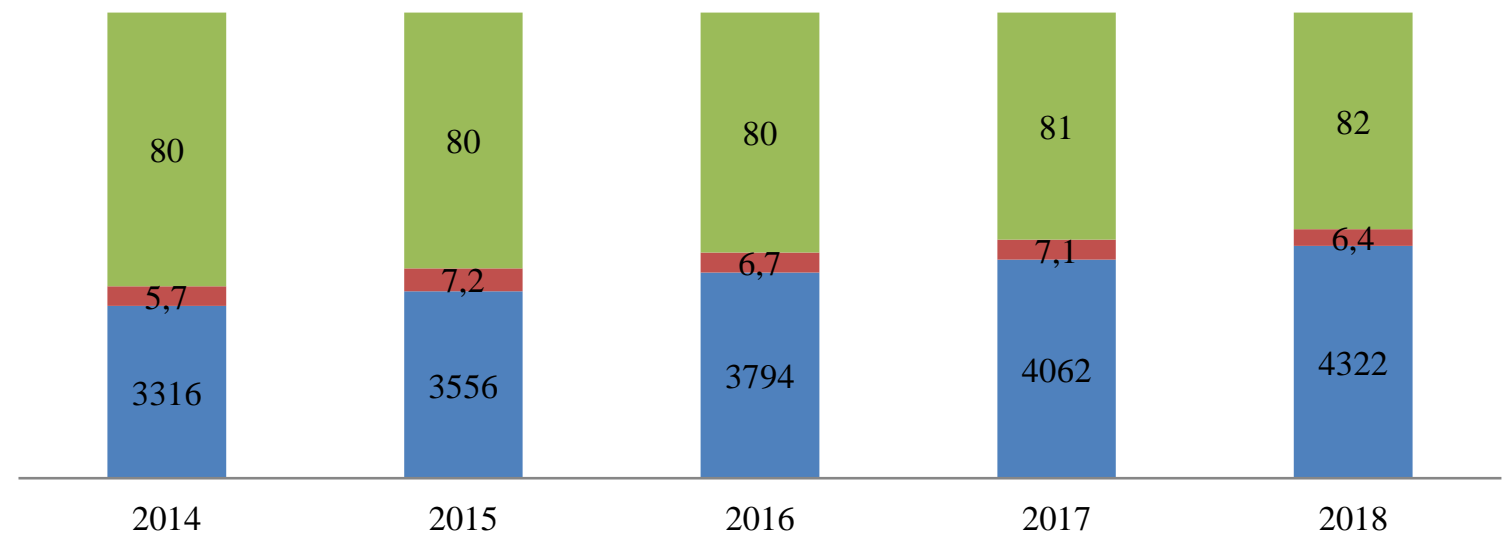

Рис. 2. Динамика увеличения общемирового пассажиропотока (2014-2018 гг.)

Fig. 2. Dynamics of global passenger traffic growth (2014-2018)

Увеличение мирового пассажиропотока, рост занятости пассажирских кресел при выполнении регулярных рейсов положительно отразились как на показателях развития авиаотрасли, так и на динамике мирового турпотока в целом [Брутян, 2019].

Ни в одном из макрорегионов за последние годы не было зафиксировано стагнации пассажирских перевозок. В 2018 году из 4,3 млрд перевезенных пассажиров на долю Европейского и Азиатско-Тихоокеанского макрорегионов приходилось 2,7 млрд или 63,1\% от общемирового пассажиропотока. Азиатско-Тихоокеанский макрорегион всегда являлся одним из активно развивающихся регионов с ростом 8-10 \% в год. Это обусловлено высокой концентрацией населения, а также высокими темпами экономического роста стран региона.

Сравнивая Латиноамериканский и Карибский макрорегионы с Ближневосточным макрорегионом, можно утверждать, что население Ближневосточного региона путешествует чаще на дальние расстояния, чем латиноамериканцы, подтверждением тому служит тот факт, 
что Ближневосточный макрорегион «налетал» больше пассажиро-километров, тогда как пассажиров перевезено меньше, чем в Латиноамериканском и Карибском макрорегионе.

Африканский макрорегион отличался невысоким пассажиропотоком и его ростом, что обусловлено низким уровнем доходов в странах макрорегиона, тогда как Североамериканский и Европейский благодаря высоким доходам населения традиционно показывают стабильный рост и самую высокую загрузку кресел среди всех макрорегионов - 84 \% [Статистические данные..., 2018].

Согласно данным сервиса Flightradar24, позволяющего в режиме реального времени отслеживать расположение воздушного судна, на конец 2018 года в мире насчитывалось около 1000 авиакомпаний, базирующихся по всем материкам земного шара, кроме Антарктиды [Список авиакомпаний..., 2019].

Среди столь большого количества авиакомпаний в каждом макрорегионе имеются свои флагманские авиаперевозчики, известные во всем мире благодаря:

- высокому уровню предоставляемых услуг;

- ценовой политике;

- современному парку воздушных судов;

- широкой географии полетов;

- безопасности полетов и др.

Все перечисленные факторы позволяли увеличивать пассажиропоток и операционную прибыль авиакомпаний.

Лидирующими игроками мирового авиационного рынка, согласно опросу TripAdvisor, стали компании Singapore Airlines, Qatar Airways, EVA Air, Emirates, Japan Airlines, Southwest Airlines, Azul, Air New Zealand, Jet2, ANA (табл. 1) [Лучшие авиакомпании..., 2019]. Эти авиакомпании вошли в десятку лучших для перелетов экономическим классом.

Таблица 1

Table 1

Рейтинг лучших авиакомпаний мира (согласно данным TripAdvisor) Rating of the best airlines in the world (according to TripAdvisor)

\begin{tabular}{|l|l|c|c|}
\hline \multicolumn{1}{|c|}{ № } & \multicolumn{1}{|c|}{ Название авиакомпании } & Страна происхождения & $\begin{array}{c}\text { Млн пассажиров } \\
2018 / 2019 \text { г. } \\
(1 \text { календарный год) }\end{array}$ \\
\hline 1. & Singapore Airlines & Сингапур & 36,1 \\
\hline 2. & Qatar Airways & Катар & 34,1 \\
\hline 3. & EVA Air & Тайвань & 12,5 \\
\hline 4. & Emirates & ОАЭ & 58,6 \\
\hline 5. & Japan Airlines & Япония & 8,5 \\
\hline 6. & Southwest Airlines & США & 34,4 \\
\hline 7. & Azul & Бразилия & 23,1 \\
\hline 8. & Air New Zealand & Новая Зеландия & 16,9 \\
\hline 9. & Jet2 & Великобритания & 5,4 \\
\hline 10. & ANA & Япония & 62,5 \\
\hline
\end{tabular}

Британская консалтинговая компания SKYTRAX подвела итоги 2019 года, согласно которым по опросам пассажиров со всего мира лучшей признана авиакомпания «Qatar Airways». Данная компания отмечают победу в пятый раз. Также «Qatar Airways» являются лидерами в номинациях «Лучший бизнес-класс». «Лучшая авиакомпания на Ближнем Востоке». На втором месте «Singapore Airlines» - перевозчик, известный тем, что выполняет самый длинный в мире рейс «Нью-Йорк - Сингапур». Таблица лучших авиакомпаний мира, согласно рейтингу SKYTRAX, представлена в табл. 2 [World Airline Awards, 2019].

Согласно данным SKYTRAX, лучшими региональными авиакомпаниями мира в 2019 г. признаны 13 авиакомпаний в каждом регионе мира (табл. 3). Одним из основных факторов, позволяющих авиакомпаниям попасть в данный список, на наш взгляд, является выгодное географическое расположение хабов, в которых базируются авиакомпании. 
Рейтинг лучших авиакомпаний мира 2019 г., согласно данным британской консалтинговой компании SKYTRAX

Rating of the best airlines in the world in 2019, according to the British consulting company

SKYTRAX

\begin{tabular}{|l|l|c|}
\hline № & \multicolumn{1}{|c|}{ Название авиакомпании } & Страна происхождения \\
\hline 1. & Qatar Airways & Катар \\
\hline 2. & Singapore Airlines & Сингапур \\
\hline 3. & ANA All Nippon Airways & Япония \\
\hline 4. & Cathay Pacific & Гонконг \\
\hline 5. & Emirates & ОАЭ \\
\hline 6. & EVA Air & Тайвань \\
\hline 7. & Hainan Airlines & Китай \\
\hline 8. & Qantas Airways & Австралия \\
\hline 9. & Lufthansa & Германия \\
\hline 10. & Thai Airways & Тайланд \\
\hline
\end{tabular}

Таблица 3

Table 3

Рейтинг лучших региональных авиакомпании мира в 2019 г., согласно данным британской консалтинговой компании SKYTRAX

Rating of the best regional airlines in the world in 2019, according to the British consulting company SKYTRAX

\begin{tabular}{|l|l|l|}
\hline \multicolumn{1}{|c|}{ Регион } & Название авиакомпании & \multicolumn{1}{c|}{$\begin{array}{c}\text { Страна } \\
\text { происхождения }\end{array}$} \\
\hline Северная Европа & Finnair & Финляндия \\
\hline Западная Европа & Lufthansa & Германия \\
\hline Восточная Европа & Aeroflot & Россия \\
\hline Африка & Ethiopian Airlines & Эфиопия \\
\hline Австралия & Qantas Airlines & Австралия \\
\hline Центральная Азия / Индия & Air Astana & Казахстан \\
\hline Китай & Hainan Airlines & Китай \\
\hline Центральная Америка & Copa Airlines & Панама \\
\hline Южная Америка & LATAM & Чили \\
\hline Северная Америка & Air Canada & Канада \\
\hline Азия & Singapore Airlines & Сингапур \\
\hline Западная Азия & Qatar Airways & Катар \\
\hline Европа & Lufthansa & Германия \\
\hline
\end{tabular}

Лучшей авиакомпанией в Восточной Европе была признана авиакомпания «Аэрофлот», что подтверждает наличие всех предпосылок для успешного ее позиционирования на рынке авиационных услуг как связующей авиакомпании между Европой и Азией.

В настоящее время все авиакомпании и авиационная отрасль в целом столкнулись с самым серьезным вызовом за всю историю современной авиации, попав в «идеальный шторм», вызванный новым стремительным и масштабным кризисом, обусловленным пандемией коронавируса и ее последствиями.

Международная ассоциация воздушного транспорта (IATA) заявляет, что никогда в истории авиационная отрасль не сталкивалась с подобной ситуацией. 95 \% парка воздушных судов остановилось. Правительства закрывают границы, наиболее неблагополучные регионы вводят режим карантина, пассажиры возвращают билеты, и авиакомпании вынуждены массово отменять рейсы, подвергаясь огромным убыткам. 
В апреле пассажиропоток российских авиакомпаний упал на $92 \%$. Официальной мировой статистики еще нет, но результаты будут сопоставимыми. Достаточно обратить внимание на:

- заявления о банкротствах национальных перевозчиков ЮАР, Маврикия, Колумбии;

- объявления о значительных сокращениях в United Airlines, Delta, Virgin Atlantic, Qatar Airways, авиастроительных концернах Airbus и Boeing и многих других компаниях;

- продажу всех акций авиакомпаний холдингом Berkshire Hathaway миллиардера Уоррена Баффетта;

- начало возврата авиационной техники лизингодателям;

- первые отказы авиакомпаний от оплаты счетов по международным соглашениям о взаимном признании бланков перевозочной документации.

По данным IATA, отрасль поддерживала около 65,5 млн рабочих мест во всем мире, включая 10,5 млн сотрудников в аэропортах и авиакомпаниях. Цепная реакция задействовала всех пользователей, партнеров и в первую очередь самих производителей услуги.

По оценке отраслевой исследовательской компании Cirium, в марте 2020 г. количество авиарейсов в мире сократилось на 63 \% относительно аналогичного периода 2019 года.

Китайские и азиатские авиалинии первыми ощутили пандемийные последствия, затем ситуация проецировалась на американские и европейские авиакомпании. Все компании от австралийской Quantas до гонконгской Cathay Pacific, от немецкой Lufthansa до американской United Airlines столкнулись с массовой отменой бронирований. Так, австралийская Qantas объявила, что отменит четверть международных рейсов, запланированных на ближайшие полгода. О резком сокращении количества рейсов объявила немецкая авиакомпания Lufthansa. Air France также отменила 3600 перелетов уже в марте, сократив свои перевозки в Европе на $25 \%$. В США из-за пандемии пассажирских авиаперелётов стало на $95 \%$ меньше. В тридцатидневный период с 14 марта по 12 апреля 2020 года было запланировано около 245000 авиаперелётов между США и Европой с участием около 5,5 млн пассажиров. Отмена только этих рейсов обернулась потерей выручки в \$2 млрд [Пассажирские авиаперевозки..., 2020].

Сильнее всего пострадал Лондонский аэропорт Хитроу, который за этот период должен был принять 820 тыс. пассажиров. В тройку наиболее сильно пострадавших воздушных гаваней также вошли Международный аэропорт Париж - Шарль-де-Голль (370 тыс.) и Международный аэропорт Франкфурт-на-Майне (340 тыс.). Аэропорты в Амстердаме и Дублине не досчитались 290 тыс. и 160 тыс. пассажиров соответственно [Пассажирские авиаперевозки..., 2020].

Ассоциация эксплуатантов воздушного транспорта (АЭВТ, объединяет крупнейшие авиакомпании России, за исключением «Аэрофлота») оценила потери российских авиаперевозчиков после частичного закрытия авиасообщения с другими странами в 500 млн руб. в сутки. В конце марта регулярные и чартерные рейсы в другие страны были приостановлены полностью. Акции «Аэрофлота» подешевели на 4,33\%, капитализация снизилась до 80,075 млрд руб. Возможные убытки российских авиакомпаний от ограничения полетов за рубеж из-за пандемии коронавируса - 70-100 млрд руб. в 2020 году. В конце апреля Росавиация разрешила перевозить грузы в салоне пассажирских самолетов семи российским авиакомпаниям. В их числе: «Аэрофлот», «Уральские авиалинии», «Nordwind Airlines», «Россия», «Azur Air», «Икар» и «Royal Flight». На этот шаг ведомство пошло из-за снижения спроса на пассажирские авиаперевозки, вызванного пандемией коронавируса. Авиакомпания «Utair» вывела из оборота более половины самолетов. «Уральские авиалинии» перепрофилировали часть своего авиапарка под грузовой [Полет в «цифре»..., 2020].

По оценке ИАТА, более трети потерь в отрасли придется на китайские компании. Благодаря стремительному развитию туризма в Китае у местных авиаперевозчиков в последние годы отмечался значительный рост, кроме того, компании планировали в ближайшее время выйти на американский рынок. Однако коронавирус внес свои коррективы в их планы, и теперь многим приходится бороться за выживание. По данным британской исследовательской компании OAG, уже в феврале китайские авиалинии снизили объем внутренних перевозок на 
10,4 млн посадочных мест. ИАТА сообщает, что в Китае на апрель забронировано на $80 \%$ меньше билетов, чем в аналогичный период в прошлом году [Ангус Уитли, 2020].

В сложившихся условиях государственная помощь - это единственный шанс на спасение авиакомпаний. «Большая тройка» авиаперевозчиков Китая (China Southern Airlines, Air China и China Eastern Airlines) находится под контролем правительства страны, которое заявило о готовности оказать им дополнительную финансовую помощь в кризисный период. Власти Китая объявили, что просубсидируют компании, выполняющие международные авиарейсы, и выплатят им по 0,0528 юаня за 1 км маршрута в расчете на одного пассажира. Так, за перелет по маршруту Лондон - Пекин, протяженность которого составляет 8175 км, правительство заплатит авиакомпании 432 юаня (\$62) в расчете на одного пассажира.

По данным OAG, в марте китайские авиаперевозчики начали возвращать внутренние рейсы в свое расписание и продавать билеты на них по низким ценам. Так, стоимость 3,5-часового перелета из Шанхая в Чэнду составила 140 юаней (примерно \$20). Это почти в десять раз ниже, чем в сентябре 2019 года [Ангус Уитли, 2020].

К концу апреля 2020 года простаивало в общей сложности 16 тысяч пассажирских самолетов [Пассажирские авиаперевозки..., 2020]. Для двух третей лайнеров главной задачей является обеспечение таких условий на земле, чтобы техника сохраняла свою летную готовность к моменту восстановления рынка. Очевидно, что не всем авиалиниям удастся пережить пандемию. Больше всего рискуют небольшие авиакомпании и лоукостеры [Колодко Гжегож В., 2020, Лысенков П.С., 2020, Мизинцева М.Ф., 2020].

Для решения таких срочных проблем во всем мире принимаются скоординированные меры авиационных властей и бизнеса:

- прямая финансовая поддержка перевозчиков;

- отсрочки по оплатам навигационных и других сборов, налогов, по лизинговым платежам; предоставление поставщиками услуг скидок перевозчикам;

- дополнительные разрешения на перевозку грузов, в том числе в специально переоборудованных в сжатые сроки салонах пассажирских воздушных судов;

- возможная легализация ваучеров как замены возврата денег за авиабилеты.

На сегодняшний день Международный совет аэропортов и Международная ассоциация воздушного транспорта выпустили совместный документ под названием «Безопасный перезапуск авиации - совместный подход МСА и ИАТА», в котором содержится обращение к правительствам и обоснование последовательности принятия новых мер в отношении аэропортов и авиакомпаний в посткоронавирусную эпоху.

Также Международная ассоциация воздушного транспорта (IATA) обратилась к странам мира с просьбой снизить парковочные тарифы - в обычных условиях они обычно не превышают $2 \%$ доходов аэропортов, но в настоящее время от них зависит выживание авиакомпаний. Издержки на парковку для авиакомпаний весьма существенны - большому самолету стоянка в аэропорту может обходиться в тысячу долларов в день [Манвелидзе, 2018; Пассажирские авиаперевозки..., 2020].

Что касается российской авиационной отрасли, то она также погружена в полный хаос и неопределенность. Трудно предположить, когда откроют границы, с каких маршрутов будут возобновлять перелеты, как будет восстанавливаться платежеспособность населения и спрос, каким образом будет оптимизирован флот и персонал.

Российские авиакомпании рассчитывают на государственную поддержку, без которой авиаотрасль не восстановится. В разных странах цифры господдержки варьируются. Так, в США выделяется около $\$ 50$ млрд на десять системообразующих авиакомпаний, Lufthansa должна получить около €9 млрд, Air France/KLM - €7 млрд В России, по оценкам экспертов, для сохранения показателей авиаперевозок на докризисном уровне потребуется не менее 400 млрд руб. [Полет в «цифре..., 2020].

Правительство консолидирует ресурсы, необходимые для оказания поддержки. Эти средства пойдут на лизинг авиационной техники, на пополнение оборотных средств, на выплаты заработных плат, оплату стоянки воздушных судов. Реструктуризацию лизинговых 
обязательств и параметры реструктуризации авиакомпании обсуждают со своими лизингодателями, для многих из них они являются важными партнерами.

Также правительством России утверждены субсидии авиакомпаниям, которые участвовали в вывозе граждан из-за рубежа в связи с распространением коронавирусной инфекции. Субсидии авиакомпаний предполагают возмещение их затрат на авиатопливо, горюче-смазочные материалы, обслуживание в аэропортах, ремонт самолетов, бортовое питание, оплату труда летного и технического персонала, расходы по аренде и лизингу воздушного судна.

\section{Заключение}

Многие аналитики отмечают, что до сих пор авиакомпаниям удавалось преодолевать кризисные ситуации. Из-за эпидемии SARS в 2003 году авиаперевозчики потеряли \$6 млрд, но смогли выйти на прежний уровень всего за девять месяцев. На этот раз может помочь падение цен на нефть, т. к. топливо является одной из основных статей расхода авиакомпаний. Безусловно, для любой проблемы рано или поздно находятся решения. Очевидным является тот факт, что сгладить последствия нынешней экономической нестабильности без эффективной государственной поддержки не удастся. Но и менеджменту компаний необходимо разрабатывать новые стратегии, научиться использовать новые инструменты и стандарты, перспективные технологии и неординарные подходы, мобилизовать все возможности для дальнейшего развития, которые непременно откроются, так как последствия кризиса приводят к необходимым для дальнейшего развития позитивным изменениям.

В сложившейся реальности пандемии на поверхности оказались давно существующие проблемы гражданской авиации, в частности, отсутствие цифровой инфраструктуры взаимодействия авиапредприятий [Полет в «цифре.., 2020]. Международные стандарты обмена информацией представителей авиаотрасли в России не всегда соблюдались. Объемы необходимых к передаче данных о каждом отправляемом рейсе, оказываемой услуге, обрабатываемом грузе или почте огромны, а инфраструктура для обеспечения этого процесса до сих пор отсутствовала. Безусловно, это инструмент к мощному преобразованию бизнеса, здесь скрыт огромный потенциал и для сокращения затрат, и для наращивания оборотов. Нейтральные цифровые платформы и сервисы, обеспечивающие взаимодействие по принципу «многие ко многим», процессинг производственных данных об авиаперевозках, контроль соблюдения мировых и отраслевых стандартов по работе с данными призваны вывести авиакомпании и их партнеров на новый уровень. Цифровая трансформация должна изменить структуру взаимодействия контрагентов. Ни одна рабочая группа, состоявшая из представителей авиакомпаний и аэропортов, не показала жизнеспособного результата в сложившейся ситуации. И сейчас как никогда время решать эти задачи.

Таким образом, пандемия стала новым серьезным вызовом для гражданской авиации, радикально изменив полетный ландшафт и сложившиеся тренды в авиаотрасли. В настоящее время однозначно не существует единых мер, которые могли бы снизить все риски возобновления авиаперевозок. Но очевидным является то, что решение всех стратегических задач возможно только при консолидации усилий всех сторон и активном вовлечении государства, так как в его задачи входит обеспечение комфортных условий для ведения бизнеса. При этом для достижения сбалансированного и эффективного перезапуска отрасли необходим глобальный подход, основанный на оценке мер по снижению рисков восстановления отрасли с необходимостью разблокировать экономику и обеспечить возможности пассажирских авиаперелетов.

\section{Список литературы}

1. Ангус Уитли, Чуньин Чжан. 2020. Жесткая посадка: чем коронавирус грозит авиакомпаниям URL: https://pro.rbc.ru/news/5e6f9dc79a79479c9f49228e (дата обращения: 24 мая 2020).

2. Брутян М.M. 2019. Мировой рынок гражданской авиации: текущее состояние и прогноз развития. Вестник Евразийской науки, 1, URL: https:/esj.today/PDF/20ECVN119.pdf (дата обращения: 20 апреля 2020). 
3. Губенко А.В., Растова Ю.И., Панкратова А.Р. 2019. Современное состояние и перспективы развития рынка пассажирских авиаперевозок в России. Научный журнал НИУ ИТМО. Серия Экономика и экологический менеджмент, 2: 82-90

4. Годовые доклады Совета. Международная организация гражданской авиации (ИКAO) URL: https://www.icao.int/publications/Pages/annual-reports.aspx (дата обращения: 25 мая 2020).

5. Деловой авиационный портал ATO.ru URL: http://www.ato.ru/content/proletet-nad-polyusomlegko-delat-eto-regulyarno-dorogo (дата обращения: 22 мая 2020).

6. Интернет-журнал для независимых путешественников. URL: https://34travel.me/post/worldairline-awards-2019 (дата обращения: 28 мая 2020).

7. История развития гражданской авиации URL: https://dream-air.ru/istoriya-razvitiyagrazhdanskoj-aviacii.html (дата обращения: 24 мая 2020).

8.Колодко Гжегож В. 2020. Последствия. Экономика и Политика в постпандемическом мире. Вопросы экономики, 5: 25-44.

9. Лучшие авиакомпании мира - конкурс Tripadvisor Travellers URL: https://www.tripadvisor.ru/TravelersChoice-Airlines (дата обращения: 25 мая 2020).

10.Лысенков П.С. 2020. Кризис и падение в авиаотрасли 2020. Modern Science. Институт стратегических исследований. Москва, 5-1: 71-74.

11. Lufthansa отменяет $95 \%$ рейсов из-за коронавируса. URL: https://www.kommersant.ru/doc/ 4293103 (дата обращения: 25 мая 2020).

12. Мизинцева М.Ф., Гербина Т.В., Чугрина М.A. 2020. Экономика эпидемий. Влияние COVID19 на мировую экономику (обзор). Пандемия COVID-19. Биология и Экономика. Специальный выпуск: информационно-аналитический сборник. Издательство «Перо». Москва: 61-102.

13. Мальцев А.А., Матвеева А.В. 2018. Международные пассажирские авиаперевозки: детерминанты взрывного роста. Управленец, 9 (3): 26-31.

14. Манвелидзе А.Б. 2018. Расходы на эксплуатацию воздушных судов крупных американских авиаперевозчиков. Стратегические решения и риск-менеджмент, 4(109): 72-91. (дата обращения: 20 мая 2020).

15.Международная ассоциация воздушного транспорта. Официальный сайт. URL: https://www.iata.org/ (дата обращения: 20 мая 2020).

16. Полет в «цифре»: что поможет авиаотрасли выжить после пандемии URL: https://pro.rbc.ru/news/5ebd50799a794715a42294eb (дата обращения: 25 мая 2020). 2020).

17. Пассажирские авиаперевозки http://www.tadviser.ru/index.php (дата обращения: 22 мая

18. Рейтинг самых прибыльных авиакомпаний мира URL: https://wchains.com/ratings/ turnover/airlines.html (дата обращения: 28 мая 2020).

19. Статистические данные о результатах деятельности воздушного транспорта в 2018 году от

ИКАО URL: https://www.icao.int/annual-report-2018/Documents/Annual.Report. 2018_Air\%20 Transport\%20Statistics.pdf (дата обращения: 27 мая 2020).

20. Список авиакомпаний согласно данным сервиса Flightradar24 URL: https://www.flightradar24.com/data/airlines (дата обращения: 23 мая 2020).

21. International Tourism Highlights, 2019 Edition URL: https://www.e-unwto.org/doi/pdf/ 10.18111/ 9789284421152 (accessed 27, May 2020).

22. World Airline Awards. URL: https://www.worldairlineawards.com/worlds-top-10-airlines-2019/ (accessed 24, May 2020).

\section{References}

1. Angus Whitley, Chunying Zhang. 2020. Hard landing: what coronavirus threatens airlines. URL: https://pro.rbc.ru/news/5e6f9dc79a79479c9f49228e (accessed 24, May 2020).

2. Brutyan M.M. 2019. World market of civil aviation: current state and forecast of development. The Eurasian Scientific Journal, [online] 1(11). URL: https://esj.today/PDF/20ECVN119.pdf (accessed 20, April 2019).

3. Gubenko A.V., Rastova Yu. I., Pankratova A. R. 2019. Current state and prospects of development of the passenger air transport market in Russia. Scientific journal of the ITMO University. Economics and environmental management series, 2: 82-90.

4. Annual reports of the Council. International civil aviation organization (ICAO). URL: https://www.icao.int/publications/Pages/annual-reports.aspx (accessed 25, May 2020). 
5. Business aviation portal ATO.ru URL: http://www.ato.ru/content/proletet-nad-polyusom-legkodelat-eto-regulyarno-dorogo (accessed 22, May 2020).

6. Online magazine for independent travelers. URL: https://34travel.me/post/world-airline-awards2019 (accessed 28, May 2020).

7. The history of the development of civil aviation. URL: https://dream-air.ru/istoriya-razvitiyagrazhdanskoj-aviacii.html (accessed 24, May 2020).

8.Kolodko Grzegorz W., 2020. Effects. Economics and Politics in the post-tandem world. Questions of Economics, 5: 25-44.

9. Best airlines in the world - Tripadvisor travelers competition. URL: https://www.tripadvisor.ru/TravelersChoice-Airlines (accessed 25, May 2020).

10.Lysenkov P. S. 2020. Crisis and fall in the aviation industry 2020. Modern Science. Strategic Research Institute. Moscow, 5-1: 71-74.

11. Lufthansa cancels $95 \%$ of flights due to coronavirus. URL: https://www.kommersant.ru/doc/ 4293103 (accessed 25, May 2020).

12. Mizintseva M. F., Gerbina T. V., Churkina M. A. 2020. The Economics of epidemics. The impact of COVID-19 on the world economy (review). The COVID-19 pandemic. Biology and Economics. Special issue: information and analytical collection. Publishing House "Pero". Moscow: 61-102.

13. Mal'cev A.A., Matveeva A.V. 2018. Mezhdunarodnye passazhirskie aviaperevozki: determinanty vzryvnogo rosta [International air travel: determinants of explosive growth]. Upravlenec [Manager]. 9 (3): 26-31.

14. Manvelidze A.B. 2018. Raskhody na ekspluataciyu vozdushnyh sudov krupnyh amerikanskih aviaperevozchikov [Aircraft operating costs of major US carriers]. Strategicheskie resheniya i riskmenedzhment [Strategic decisions and risk management], 4(109): 72-91 (accessed 20, May 2020).

15.International air transport Association. Official site. URL: https://www.iata.org/ (accessed 20, May 2020).

16. Flying in "digital": what will help the aviation industry survive after the pandemic. URL: https://pro.rbc.ru/news/5ebd50799a794715a42294eb (accessed 25, May 2020).

17. Passenger air transport. URL: http://www.tadviser.ru/index.php (accessed 22, May 2020).

18. Rating of the most profitable airlines in the world. URL: https://wchains.com/ratings/ turnover/airlines.html (accessed 28, May 2020).

19. Statistics on air transport performance in 2018 from the ICAO. URL: https://www.icao.int/annualreport-2018/Documents/Annual.Report. 2018_Air\%20Transport\%20Statistics. pdf (accessed 27, May 2020).

20. List of airlines according to the Flightradar24 service. URL: https://www.flightradar24. com/data/airlines (accessed 23, May 2020).

21. International Tourism Highlights, 2019 Edition URL: https://www.e-unwto.org/doi/pdf/ 10.18111/ 9789284421152 (accessed 27, May 2020).

22. World Airline Awards. URL: https://www.worldairlineawards.com/worlds-top-10-airlines-2019/ (accessed 24, May 2020).

\section{ИНФОРМАЦИЯ ОБ АВТОРАХ}

Климова Татьяна Брониславовна, кандидат экономических наук, доцент, заведующая кафедрой международного туризма и гостиничного бизнеса Белгородского государственного национального исследовательского университета, Белгород, Россия

\section{INFORMATION ABOUT THE AUTHORS}

Tat'yana B. Klimova, Candidate of Economic Sciences, Associate Professor, Head of the Department of International Turism and Hotel Business, Belgorod National Research University, Belgorod, Russia 